\title{
Optimal reactive power dispatch: a bibliometric analysis
}

\author{
Ibrahim Haruna Shanono ${ }^{1 *} \mathbb{D}$, Aisha Muhammad ${ }^{2}$, Nor Rul Hasma Abdullah ${ }^{1}$ Hamdan Daniyal ${ }^{1}$ \\ and Meng Chung Tiong ${ }^{1}$
}

${ }^{*}$ Correspondence: snnibrahim01@gmail.com

${ }^{1}$ Faculty of Electrical and Electronics Engineering, Universiti Malaysia Pahang, 26600 Pekan, Pahang, Malaysia

Full list of author information is available at the end of the article

\begin{abstract}
Optimal reactive power dispatch (ORPD) plays a significant role in the control and smooth operation of the power system through the enhancement of the network's reliability, security, and economic aspects. This paper presents a bibliometric and visual analysis of ORPD-related research articles extracted from the Web of Science (WoS) database from its inception to October 29, 2019. A total of 263 articles drawn from 166 journals, published between 1989 and 2019, were retrieved and analysed using Excel, HistCite, and VOSviewer visualisation software. The total number of citations for the 263 articles ranges from 0 to 297. The top three journals with the most significant number of ORPD publications were the International Journal of Electrical Power and Energy Systems, Applied Soft Computing, and two journals qualified for the third place, IEEE Transaction on Power Systems and IET Generation Transmission and Distribution. The most active researcher is Provas Kumar Roy, with nine (9) articles from Kalyani Government Engineering College. The most trending/cited researcher is Yi Jia Cao, with 129 Total Local Citation Scores from Hunan University, Changsha. In terms of contribution by countries, India, China, Iran, and the United States were the most significant contributors with $27.8 \%, 20.9 \%, 11.8 \%$, and $8 \%$ of the total articles, respectively. The top 5 most frequently used substantive keywords to identify the trending topic and research direction were Particle Swarm Optimisation, Genetic Algorithm, Gravitational Search Algorithm, Linear Programming, Evolutional Algorithm, and Hybrid Algorithm. This study provides a detailed outline and reveals the future research directions for both experienced and novice ORPD researchers to identify research topics, questions, and collaboration partners.
\end{abstract}

Keywords: Optimal reactive power dispatch, Bibliometric analysis, Web of science, HistCite, VOSviewer

\section{Introduction}

The economic stability of any nation has a direct link with the amount of energy it generates and consumes. Therefore based on this, there is a need for stable, sustainable, sufficient as well as reliable electrical power system network. The power grid consists of three main stages, namely generation, transmission and distribution, which delivers the power to both industrial and residential consumers. The power network needs to be robust to accommodate all the dynamic factors associated with the system [1, 2].

\section{SpringerOpen}

(c) The Author(s) 2020. This article is licensed under a Creative Commons Attribution 4.0 International License, which permits use, sharing, adaptation, distribution and reproduction in any medium or format, as long as you give appropriate credit to the original author(s) and the source, provide a link to the Creative Commons licence, and indicate if changes were made. The images or other third party material in this article are included in the article's Creative Commons licence, unless indicated otherwise in a credit line to the material. If material is not included in the article's Creative Commons licence and your intended use is not permitted by statutory regulation or exceeds the permitted use, you will need to obtain permission directly from the copyright holder. To view a copy of this licence, visit http://creativeco mmons.org/licenses/by/4.0/. 
Usually, network losses in a power system vary between 5 and $10 \%$ of the total generation, which translates to millions of dollars per annum [3]. Due to the rapid voltage fluctuations caused by the variation in consumer demands, there is need to device a suitable means of maintaining a stable load bus voltage, apparent power through the lines, as well as the reactive generator power [4]. Consequently, loss minimisation, as well as voltage balancing, needs to be adequately addressed in any power system network [5-7]. The two can be controlled by regulating and monitoring the magnitude of the bus voltages, transformer tap settings and capacitive reactive power injection while adhering to the units and system constraints $[8,9]$.

Previously, ORPD problems were solved using conventional optimisation strategies, such as linear programming $[10,11]$, nonlinear programming, quadratic programming [12], Newton Rapson method, gradient-based algorithm and interior point method [13]. However, they were found to be inefficient in solving the nonlinear functions as well as discrete variables $[14,15]$, hence resulting in inaccurate solutions. Due to their disadvantages, coupled with the rapid advancement in computer technology, stochastic optimisation techniques for solving power system problems emerged. Heuristic and metaheuristic population-based strategies with stochastic transition rules, Genetic Algorithm (GA) [16, 17], Improved GA [18], Real Parameter GA [19], Adaptive GA [17], Evolutionary Strategy (ES) [20], Hybrid Evolutionary Programming [21], Particle Swarm Optimisation (PSO) [22], Hybrid PSO [23], Bacterial Foraging Optimisation (BFO) [24], Self-Adaptive Differential Evolution (SADE) [25, 26], Artificial Bee Colony (ABC) [27], Harmony Search Algorithm (HSA) [28], improved and modified HSA [29, 30], Tabu Search (TS), Gravitational Search Algorithm (GSA) [31, 32], Grey Wolf Optimisation (GWO) [33], Hybrid Firefly Algorithm (HFA) [34], Teaching-Learning-Based Optimisation algorithm (TLBO) [35], and many more were successfully applied to obtain ORPD solutions.

Bibliometric studies follow a systematic set of the procedure to quantify and analyse popular scientific articles on a specific research field/area or topic of interest [36, 37]. The outcome produced research foci and a summary of the developmental trends of the research field and the future research direction [38, 39]. The bibliometric evaluation examines bibliometric features and information such as publications, citations, as well as research study results [40-43]. It permits researchers to recognise research activities framework, qualities and patterns. The evaluation process correlates the study activities into a consistent trend of a research domain as it includes scientific research works of various contexts such as publications, institutions, authors, organisation countries and citations. It is an approach that reports on a thorough analysis of the growth of researchers $[44,45]$. Example of such technique was utilised by [46, 47] to determine the intellectual development in information security and computer technology. Bibliography study has the following advantages:

1. Writers can show the importance of their research.

2. Academic researchers can forecast future study as well as substantial influence on any specific topic.

3. Institutions can review publication efficiency and gauge the quality of their impact. 
Based on the author's knowledge, there has been no bibliometric study carried out on ORPD research field. Most of the publications focused on reviewed articles and application of optimisers to achieve optimal and reliable operation of the power system network. Hence, this paper undertakes a new twist by presenting a bibliometric analysis on ORPD published articles that are index in the Web of Science database. The steps involved in conducting the bibliometric study are shown in Fig. 1. Systematic and chronological distribution of ORPD publications, the most active ORPD scientific journals, and principal key authors, organisations/institutions along with their citations, co-citations and collaborations were visualised using Histcites and VOSviewer tools. The research outcome provides valuable insights into the current and future research trends to ORPD researchers. The whole paper is structured into

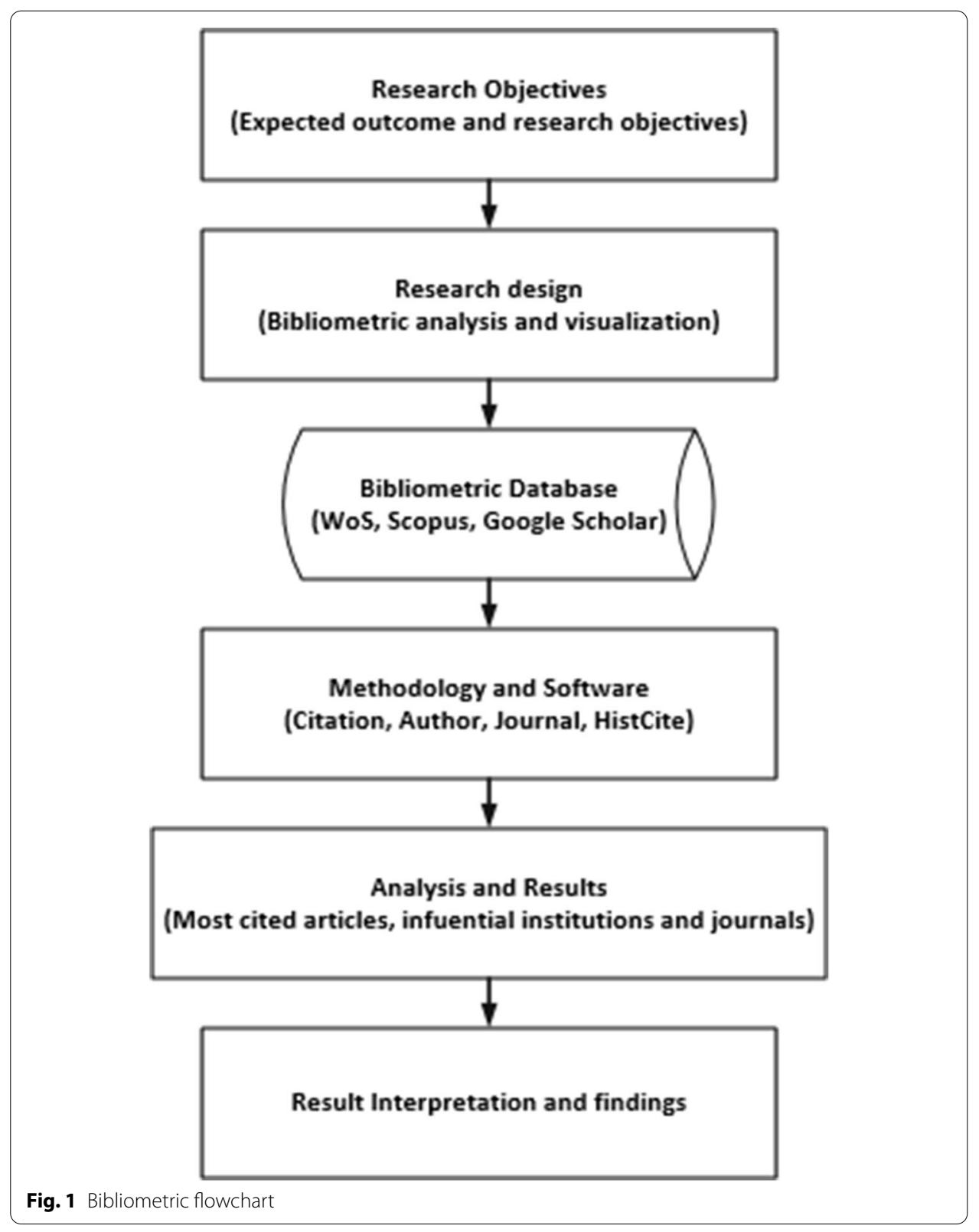


four (4) sections. "Introduction" section is the introduction section, followed by the methodology in "Methods" section. "Results and discussion" section presents the results and discussion, while "Conclusion" section draws the research conclusions.

\section{Methods}

\section{Data sources}

There are two well-known databases in Engineering, namely Web of Science (WoS) and Scopus. WoS is selected for this research due to its reputation. Secondly, due to the non-compatibility of the HisCites software with the Scopus database, a search using the phrases "Optimal reactive power dispatch", "Optimum reactive power transfer", "Optimum reactive power dispatch" and "Optimal reactive power transfer" was conducted on September 29, 2019, out of which 263 research-related articles were identified. Due to the limited number of available data, all document categories such as research articles, book chapters, proceedings and reviews were considered. All the data collation was done on the same day to avoid bias.

\section{Data extraction}

To ensure that the extracted data are error-free from irrelevant articles so that all selections are purely ORPD-related articles, the initial search result has to be manually refined three times by two independent authors. Each of the article titles was scrutinised to ensure it is genuinely an ORPD article. During the extraction, information such as accession number, citations, publication types, countries/regions, journals, were selected to be included in the extracted data.

\section{Data visualisation and analysis}

Excel, HistCites and VOSviewer were the tools used in this study. Microsoft Excel was used in both visualisation and analysis of the data. HistCites is a software used for statistical data analysis. The software is capable of identifying the key research fields. It creates individual authors historiography and equally specifies highly cited papers by providing visual results and the exact timeline of the published research articles. The software is capable of analysing publication records, citation statistics for countries and institutions. While VOSviewer is a visualisation tool that generates maps/chart with bubbles representing an author, article, city or keyword, the bubble size signifies the frequency of occurrence and the colour indicates an individual cluster. Firmly related bubbles are positioned close to each other, and the connection lines are thicker, hence signifying strong bond.

\section{Results and discussion}

A total of 263 articles were pulled out of the web of science database. It comprises 130 research articles, 126 proceedings papers, three (3) reviews, three (3) book chapters and one (1) editorial material. The Total Global Citation Scores (TGCS) and Total Local Citation Scores (TLCS) of the articles range from 0 to 297 and 0 to 67, respectively. The average total of GCS and LCS citations for the entire data is $14.6(3837 / 263)$ and $4.1(1083 / 263)$, respectively. About $23.2 \%$ of the articles $(n=61)$ receives five (5) or more local citation (TLCS) from articles within the collection. While $38 \%$ of the 
Table 1 List of articles ranked according to the highest TGCS and TLCS

\begin{tabular}{|c|c|c|c|}
\hline S/n & Author & LCS & GCS \\
\hline & Ranking based on TGCS & & \\
\hline 1 & $\begin{array}{l}\text { Zhao B et al., A multiagent-based particle swarm optimisation approach for optimal reactive } \\
\text { power dispatch, } 2005\end{array}$ & 67 & 297 \\
\hline 2 & $\begin{array}{l}\text { Wu Qh et al., Power-system optimal reactive power dispatch using evolutionary program- } \\
\text { ming, } 1995\end{array}$ & 49 & 169 \\
\hline 3 & Wu QH et al., Optimal reactive power dispatch using an adaptive genetic algorithm, 1998 & 49 & 146 \\
\hline 4 & Dai CH et al. Seeker Optimisation Algorithm for Optimal Reactive Power, 2009 & 39 & 140 \\
\hline \multirow[t]{2}{*}{ - } & Abou El et al. Differential evolution algorithm for optimal reactive power, 2011 & 0 & 109 \\
\hline & Ranking based on LCS & & \\
\hline 1 & $\begin{array}{l}\text { Zhao B et al., A multi-agent-based particle swarm optimisation approach for optimal reactive } \\
\text { power dispatch, } 2005\end{array}$ & 67 & 297 \\
\hline 2 & $\begin{array}{l}\text { Wu Qh et al., Power-system optimal reactive power dispatch using evolutionary program- } \\
\text { ming, } 1995\end{array}$ & 49 & 169 \\
\hline 3 & Wu QH et al., Optimal reactive power dispatch using an adaptive genetic algorithm, 1998 & 49 & 146 \\
\hline 4 & $\begin{array}{l}\text { Subbaraj P et al., Optimal reactive power dispatch using self-adaptive real coded genetic } \\
\text { algorithm, } 2009\end{array}$ & 41 & 102 \\
\hline 5 & Duman S et al., Optimal reactive power dispatch using a & 40 & 94 \\
\hline
\end{tabular}

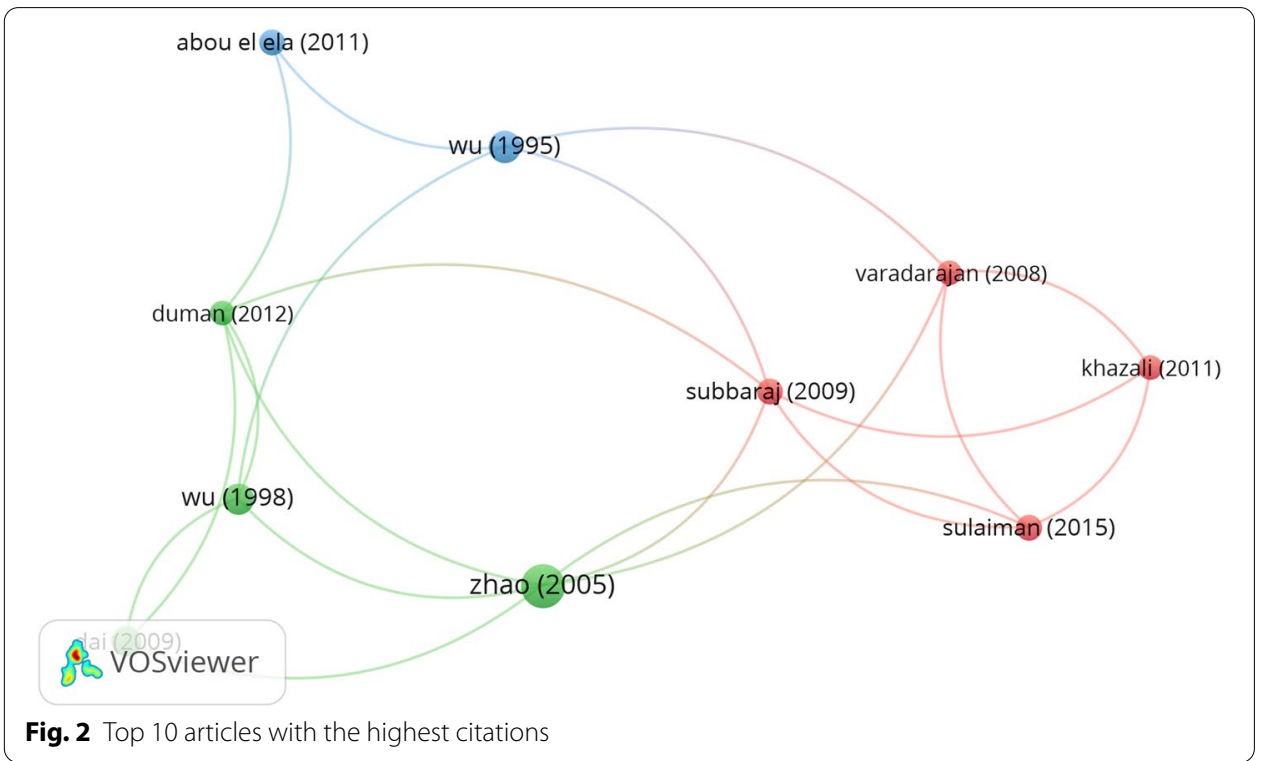

articles $(n=100)$ receives five (5) or more global citation (TGCS) from the entire articles in the web of science database. An article published in IEEE Transactions on Power Systems ( $n=17$, IF2018, 6.807) by Bo Zhao et al. of Zhejiang University, China in 2005, has the highest number of TGCS and TLCS citations of 297 and 67, respectively. Table 1 presents an extract of the top 5 research articles with the highest TGCS and TLCS. Figure 2 shows the citation visualisation network of the top 10 ORPD articles. The network is categorised into 3 clusters under how closely related the research content is with each other, and each circle signifies a journal whose size depends on the amount of citation it receives. This is used as the measure of the impact an article 
makes in the entire research field. The lines are the citation connection between the articles.

\section{Yearly publication output}

The articles selected were published between 1989 and 2019, with the exclusion of 1990, 1991, 2000 and 2001 as there was no record of any publication in those years. Figure 3 shows the number of publications and citations done per year. The left axis contains the number of published articles which is represented by the continuous red line. Based on our data, interest in ORPD started around let 80's and gradually researchers start to pick up interest, with unsteady fluctuations in the research outputs in the mid-'90s and early 2000s. The highest number of publication occurred in 2016, where 34 articles were published. Since then, research outputs has been falling rapidly, signifying a decline in research interest. Similarly, the right vertical axis represents the number of citations per year. Citation directly depends on the publication outputs and the volume of already existing literature in the research field. This is why in the early ' $80 \mathrm{~s}$, when there were no publications to refer to, the citations were zero. However, as the number of relevant articles increased in the database, both local and global citations started to rise. The highest number of TLCS and TGCS occurred in 2014 and 2011, respectively, hence indicating a rise in ORPD research interest in those years.

\section{ORPD research distribution by countries/regions}

The ORPD researchers are spread across 38 countries that cut across all the seven (7) continents. Figure 4 is a pie chart depicting the percentage of article contribution from countries having five (5) articles and above. The percentage of countries with four (4) articles and below is summed up together and tagged as "Others". India, China and Iran topped the list with $24 \%, 18 \%$ and $10 \%$, respectively, signifying the raise in ORPD research interest in the Asian continent. The 4th country is the USA with 7\%, and the 5 th is a tie between the UK and Algeria with $4 \%$, while the $6^{\text {th }}$ is Germany with $3 \%$. The rest are Turkey, Malaysia and six others who had approximately $2 \%$ each. There is an

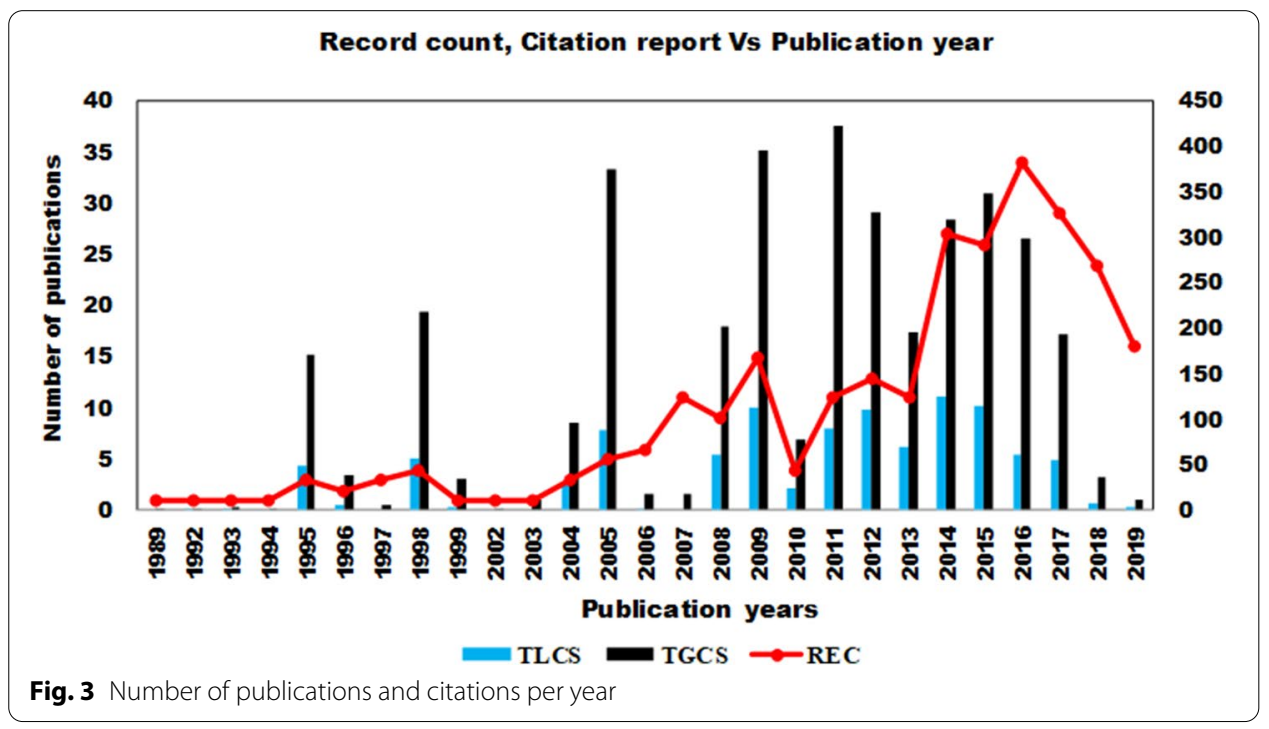



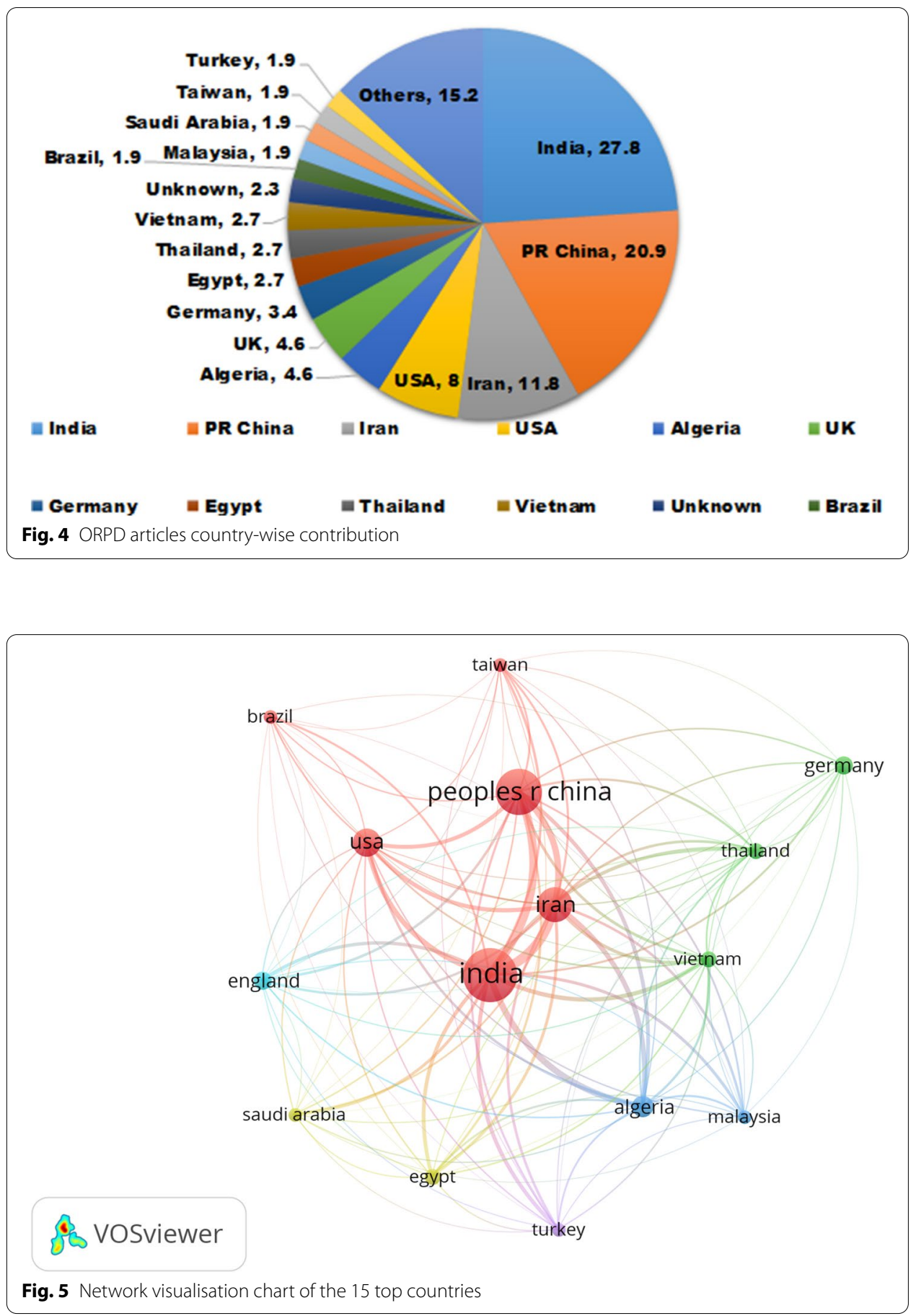

additional $2 \%$ in which the contributing country could not be ascertained, hence it is tagged as "Unknown". The remaining 22 countries with 4 or fewer documents amounted to $13 \%$ of the total.

Figure 5 shows the network visualisation chart of the top 15 countries. They were classified into three research clusters based on collaborations, co-authorship, citations and co-citations. The size of the circle signifies the level of contribution to the research field. 

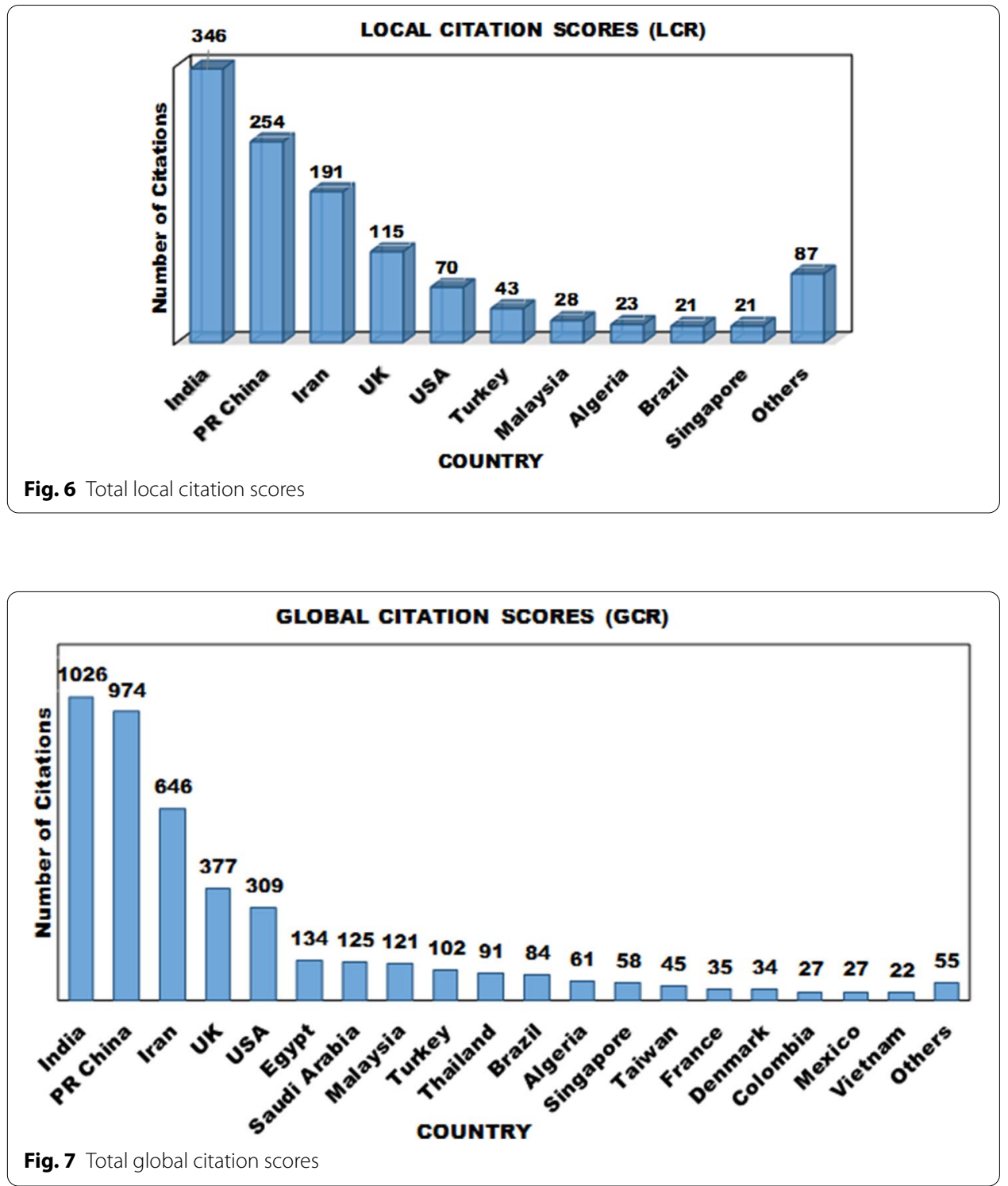

Apart from ranking countries based on the number of published articles, they were equally ranked according to the number of local (TLCS) and global (TGCS) citations they earned. This measure indicates the quality and strength of published research from those countries. Figures 6 and 7 show the chart of countries whose TLCS and TGCS are 20 and above. Interestingly, the top 3 countries with the highest publications in Fig. 4 still occupy the same position in Fig. 6 . However, the two countries that previously occupy 4 th in publications were displaced by the UK. This further proves that the number of citations earned by researchers or countries depends on the quality of the research and not the number of their publications. All countries having TLCS less than 20 were summed up, and it totalled 87 local citations.

Figure 7 presents the global citation scores. Usually, the number of citation should be higher in TGCS since it is a superset of the TLCS. TGCS is the amount of the total citations earned from the entire web of science database. Nineteen countries had 20 and 
above citations, whereas the remaining 19 countries with less than 20 citations were classified as others. The top 5 countries in the previous TLCS chart still retain their positions on the TGCS chart, which further signifies the strength and contribution they are making in the ORPD research field.

\section{ORPD research contributions based on universities and organisations}

A total of 258 organisations, universities and institutions contributed to the field of ORDP research for the period considered in this study. The key indicators used to measure the level of research contribution are the number of publications, TLCS and TGCS obtained by each organisation. Table 2 contains a list of 22 institutions and universities having a minimum of four (4) publications. The 22 universities were able to publish 131 ORPD-related articles, representing $49.8 \%$ of the total articles published by the 258 institutions/organisations. The most productive organisation is the National Institute of Technology, which is a public institution with 31 branches spread across India.

Figure 8 shows the universities/institutions visualisation chart. There are five (5) research clusters, each represented by a different colour. The clusters were based on the level of collaborations that exist between the organisations. Each cycle represents an institution/university or organisation whose collaboration strength was determined by the distance between the cycles. The line thickness linking the cycles signifies the citation strength. It is worth mentioning that the 258 institutions/organisations are located in 38 countries across the globe. Figure 9 depicts the countries and the interconnection link in terms of collaborations, citations and co-citations. India, China and Iran are the

Table 2 University/institutions with the number of publication greater than or equal to 4 articles (publications $\geq 4$ )

\begin{tabular}{ll}
\hline University/institution & Publications \\
\hline Natl Inst Technol & 12 \\
Dr BC Roy Engn Coll & 8 \\
Indian Sch Mines & 8 \\
Islamic Azad Univ & 8 \\
Univ Duisburg Essen & 8 \\
Sharif Univ Technol & 7 \\
Iran Univ Sci \&Technol & 6 \\
Jadavpur Univ & 6 \\
S China Univ Technol & 6 \\
Unknown & 6 \\
Zhejiang Univ & 6 \\
Asian Inst Technol & 5 \\
Ho Chi Minh City Univ Technol & 5 \\
Indian Inst Technol & 5 \\
Shiraz Univ Technol & 5 \\
South China Univ Technol & 5 \\
Thiagarajar Coll Engn & 5 \\
Asansol Engn Coll & 5 \\
Kalasalingam Univ & 5 \\
Kalyani Govt Engn Coll & 4 \\
Univ Tabriz & 4
\end{tabular}



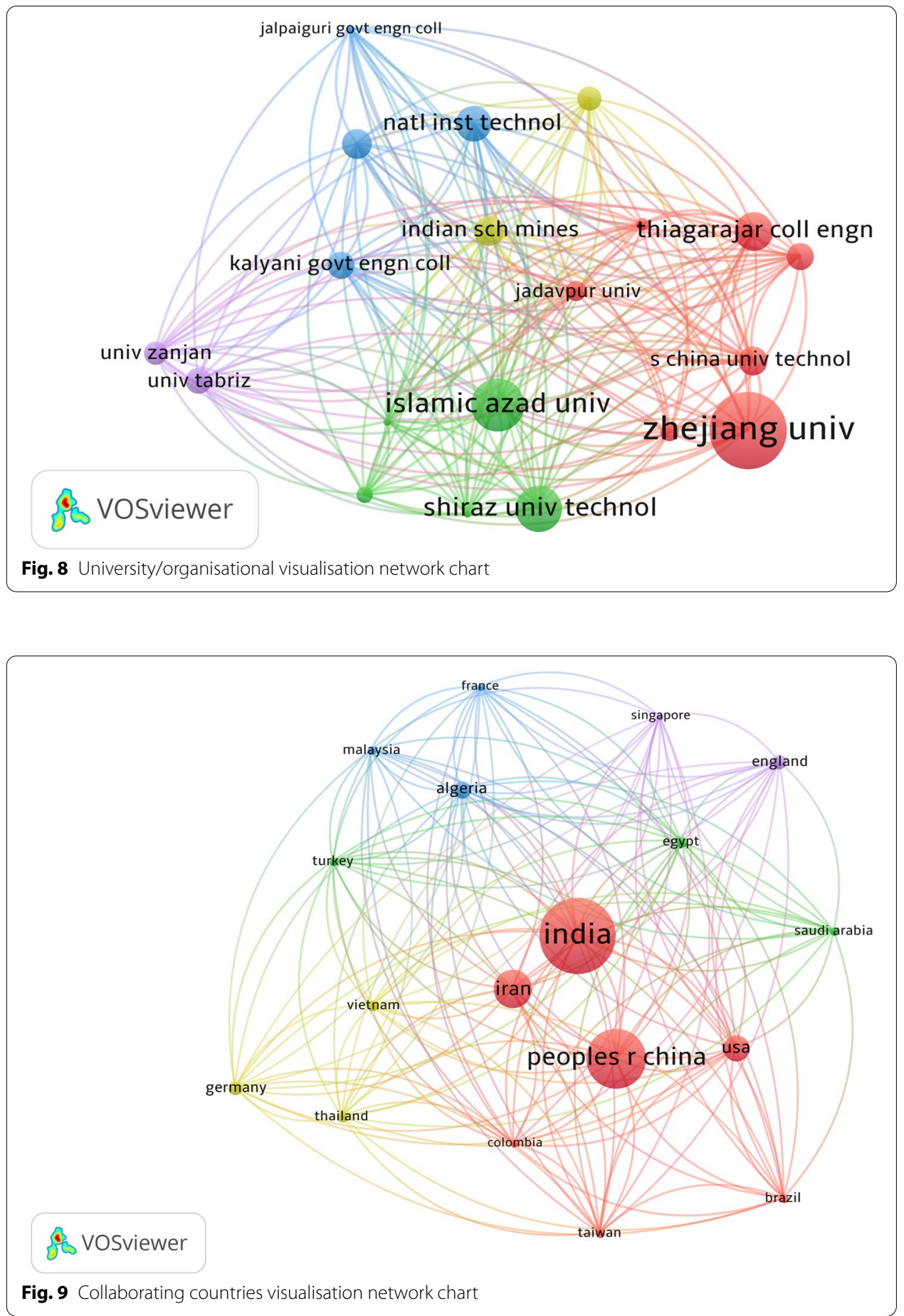

1st, 2nd and 3rd countries, respectively, with the highest location of ORPD research contributors. The research contributors (universities and organisations) are also ranked according to the number of TLCS and TGCS they earned.

Figures 10 and 11 present the TLCS and TGCS citation charts for the research collaborators. Islamic Azad University (9\%), Zhejiang University (7.4\%) and Shiraz University $(6.9 \%)$ make up the top 3 contributors in terms of local citations within the selected 

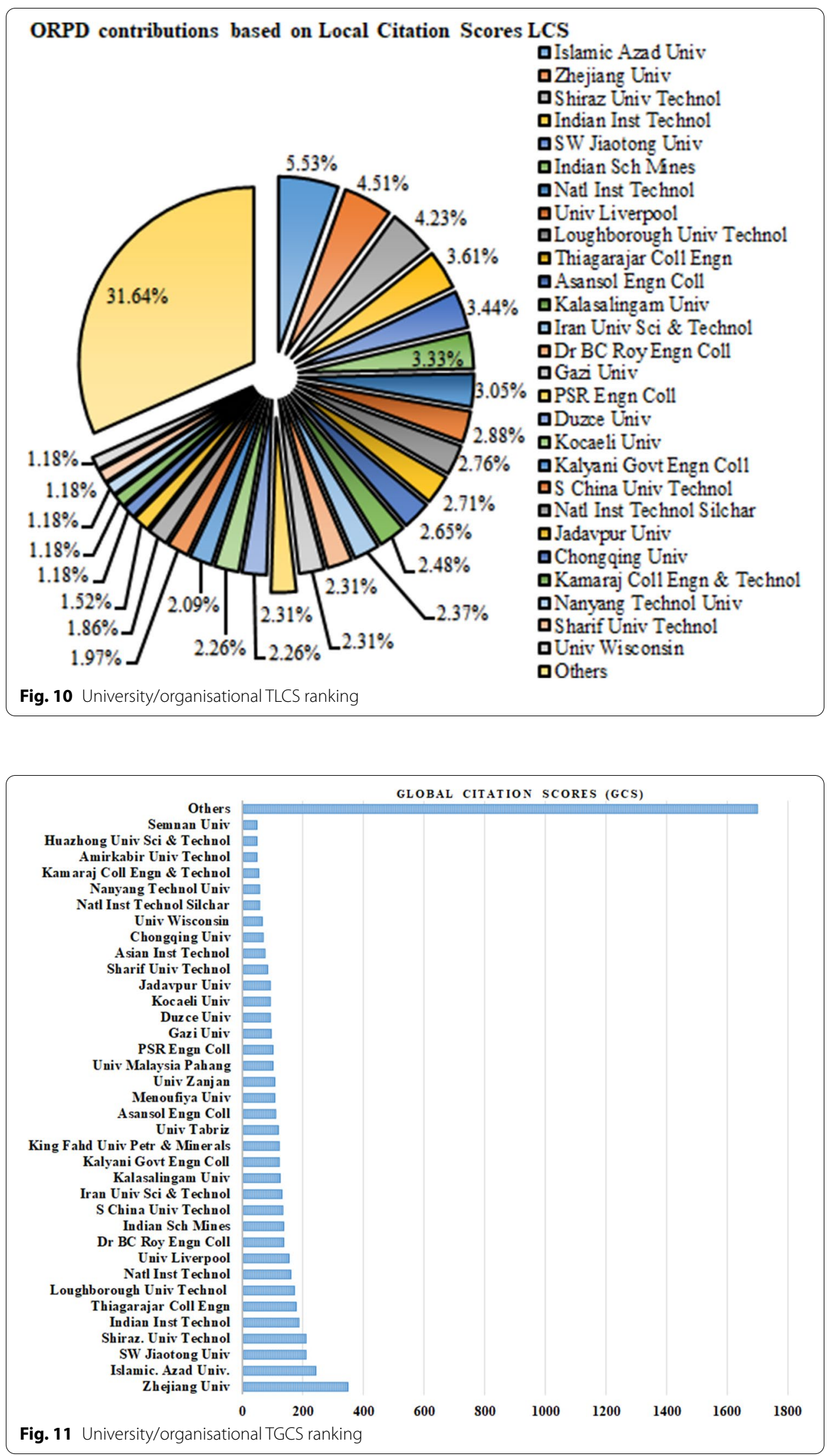
data while Zhejiang University (9.1\%), Islamic Azad University (6.3\%) and SW Jioantong University (5.5\%) took 1, 2 and 3 places, respectively, in the global citation (GCS) within the entire web of science database.

\section{Distribution of authors}

The entire 263 articles were authored by 571 authors drawn from 258 universities, institutions and organisations across the globe. Similar to the previous section, the primary measure of performance of an author was based on the number of published articles and the number of local (TLCS) and global (GLSC) citation scores earned as well as the geographical location they belong. Therefore, based on the number of articles, Roy PK topped the list with nine (9) articles representing 3.4\% of the total records, followed by Cao YJ and Erlich I with eight (8) articles each representing 3\%. Then Mukherjee V and Yesuratnam G both having seven (7) articles representing 2.7\% of the total. A total of 25 authors have four (4) articles with a combined publication of 125 articles, representing $47.53 \%$ of the total publications. The remaining $52.47 \%$ was shared among 546 authors.

Figure 12 shows the number of publications of authors with four (4) articles and above. Figure 13 presents the author's visual research clusters and interconnections. The visualisation network contains the list of authors having four (4) and above publications in the extracted data. Each circle represents an author, and closely related authors are positioned near to each other to form a cluster. There are four (4) research clusters in the visualisation network which are classified based on co-authorship, co-citations, collaborations and keywords.

Authors are equally ranked based on the earned TLCS and TGCS. TLCS and TGCS citation signifies the quality and significance of an author/researcher in his research

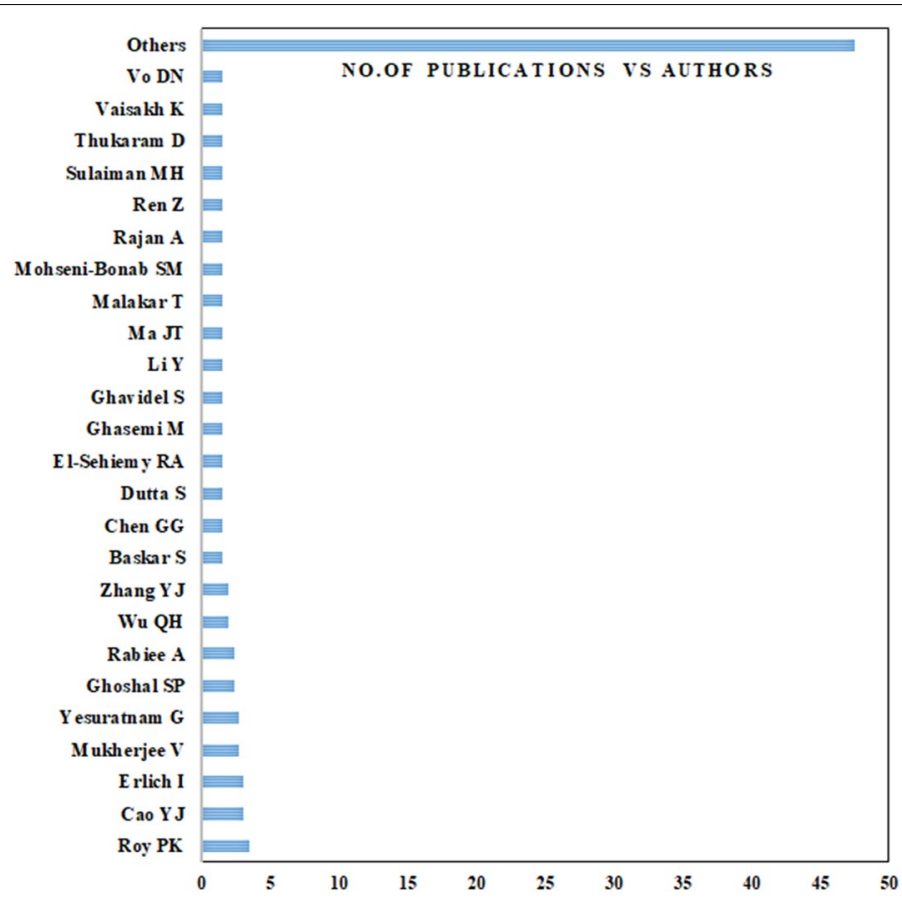

Fig. 12 Number of publications versus author 


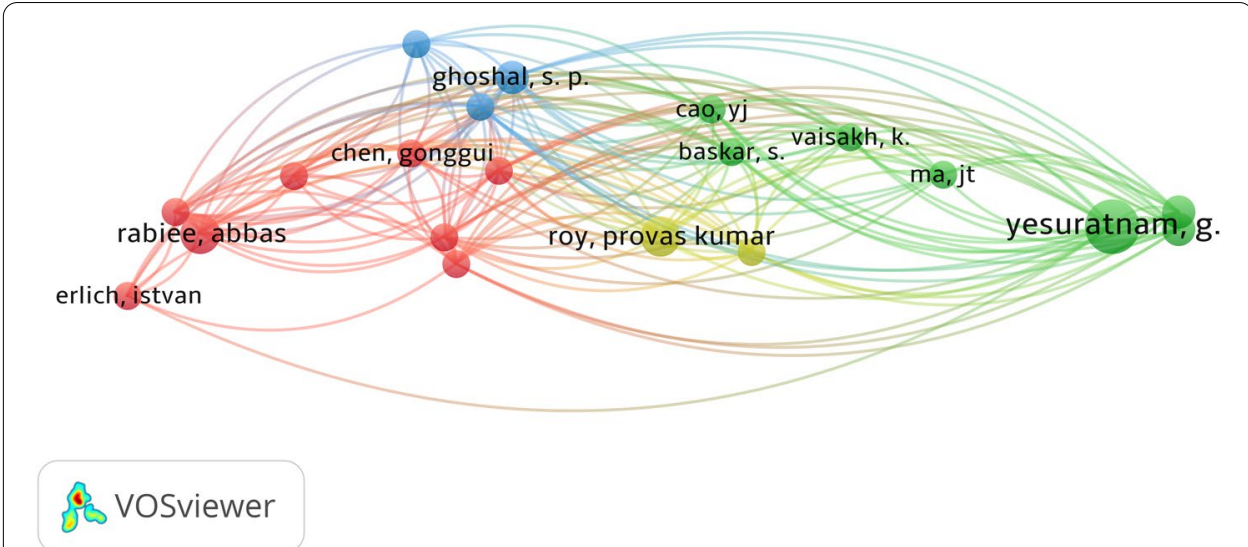

Fig. 13 Author's visualisation network chart

\section{AUTHORS TOTAL LOCAL CITATION SCORES (TLCS)}
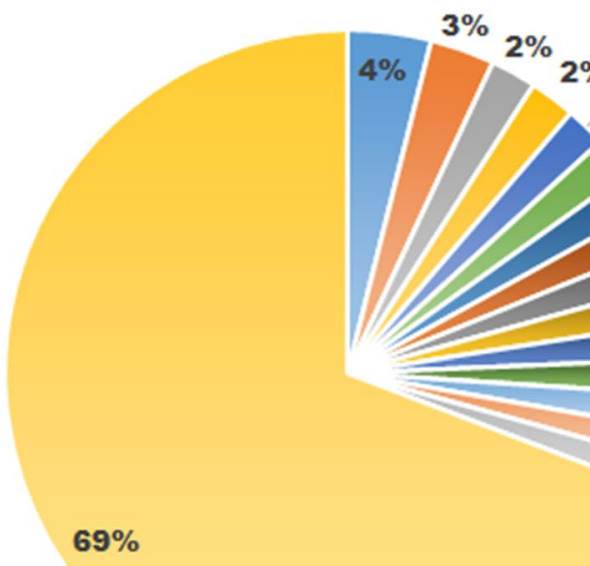

$2 \%$

$2 \%$

$2 \%$

$2 \%$

$2 \%$

$2 \%$

$2 \%$

$2 \%$

$2 \%$

$\mathbf{2 \%}$

$69 \%$

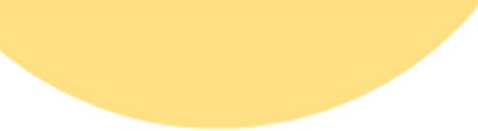

" Cao YJ

= Wu QH

Guo CX

Zhao B

Ghasemi M

Ghavidel S

- Chen WR

- Dai CH

= Zhang XX

= Zhu YF

- Mukherjee V

- Swarup KS

Varadarajan $\mathbf{M}$

Ghanbarian MM

Ma JT

others

Fig. 14 Author's TLCS ranking

domain. Figures 14 and 15 present the graphical representation of authors TLCS and TGCS.

Authors with 50 local citation scores and above were selected, while those with less are combined and categorised as "Others".

A total of 15 authors satisfied this condition and had a combined TLCS total of 30.8\%, while $69.2 \%$ went to the remaining 531 authors. Based on the obtained result, Cao YJ has a total of 129 citations, amounting to $3.93 \%$ of the total, hence making him be the top author in ORPD research family in the TLCS citations category. The 2nd position is $\mathrm{Wu}$ QH with 3.05\%, followed by Guo CX and Zhao B in the 3rd place with $2.16 \%$ each. The 


\section{AUTHORS TOTAL GLOBAL CITATION SCORES (TGCS)}

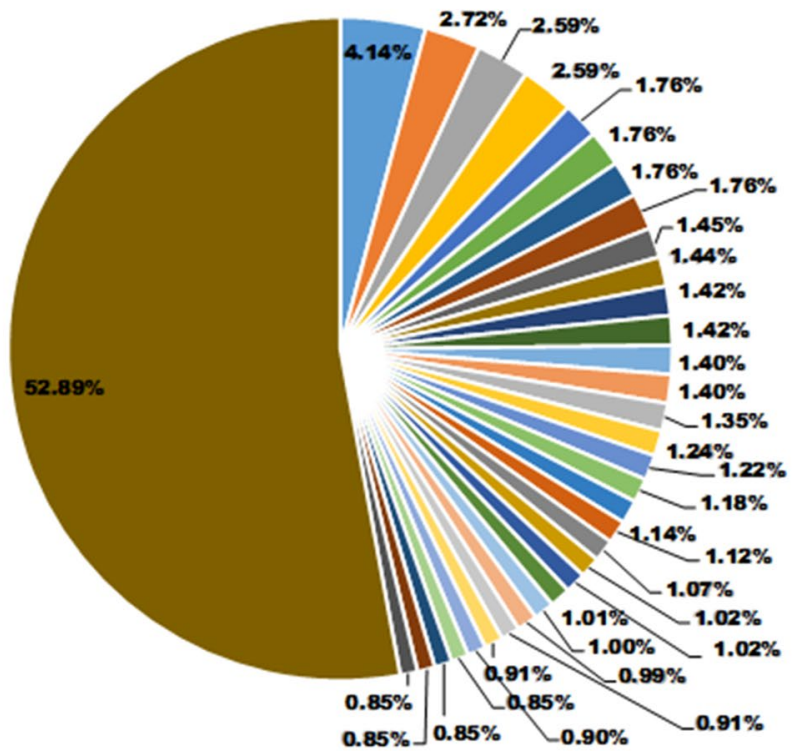

- Cao YJ

= Wu QH

Zhao B

- Chen WR

Dai CH

= Zhang XX

- Zhu YF

- Ma JT

- Baskar S

- Swarup KS

- Varadarajan M

Ghasemi M

Ghavidel S

= Roy PK

Jeyadevis

- Wen JY

Rabiee A

- Mukhe ijee V

" Ghoshal SP

" Ghanbarian MM

- Abido MA

" Mandal B

- Sulaiman MH

Mustaffa Z

- Kalantar M

Abou EI Ela AA

Spea SR

Mohseni-Bonab SM

Niman 0

n Mohamed MR

- Rajnarayanan PN

Subbaraj P

- Others

Fig. 15 Author's TGCS ranking

global citation scores (TGCS) measured the author's citation over the entire web of science database, i.e. including citations not part of the ORPD collections.

For the TGCS, authors with 100 and above citations were said to be considered. Based on that, 33 authors were selected, which amounted to $47.11 \%$ of the total TGCS citations. The remaining 501 authors shared the remainder of $52.89 \%$. Figure 15 shows the pie chart of the details.

The top authors Cao YJ, Wu QH, Guo CX and Zhao B, occupied the same position as in the previous TLCS chart, with a percentage of $4.14 \%, 2.72 \%$ and $2.59 \%$, respectively. This means that the four authors produce novel and high-quality articles that are equally relevant to other research fields. There are interchanges in other authors' positions, such as the case of the 5th position, which Ghasemi M and Ghavidel S had with 1.98\% each, shifted to 13th position in the TGCS citation table.

\section{Journal distribution}

All the 263 ORPD articles were published in $168 \mathrm{Web}$ of science index journals. The number of ORPD articles published by each journal ranges from 1 to 23 articles. Figure 16 shows the journal visualisation network, indicating the bibliometric coupling existing between the top 30 journals with each having at least two published ORPD articles. The 30 journals were classified into 6 clusters based on the article content similarities, citations and co-citations between the articles. Each cycle represents an individual journal and the bigger the circle size, the higher the journal productivity and influence in ORPD research field. Table 3 shows the summary of journals that published at least two ORPD-related research article. 


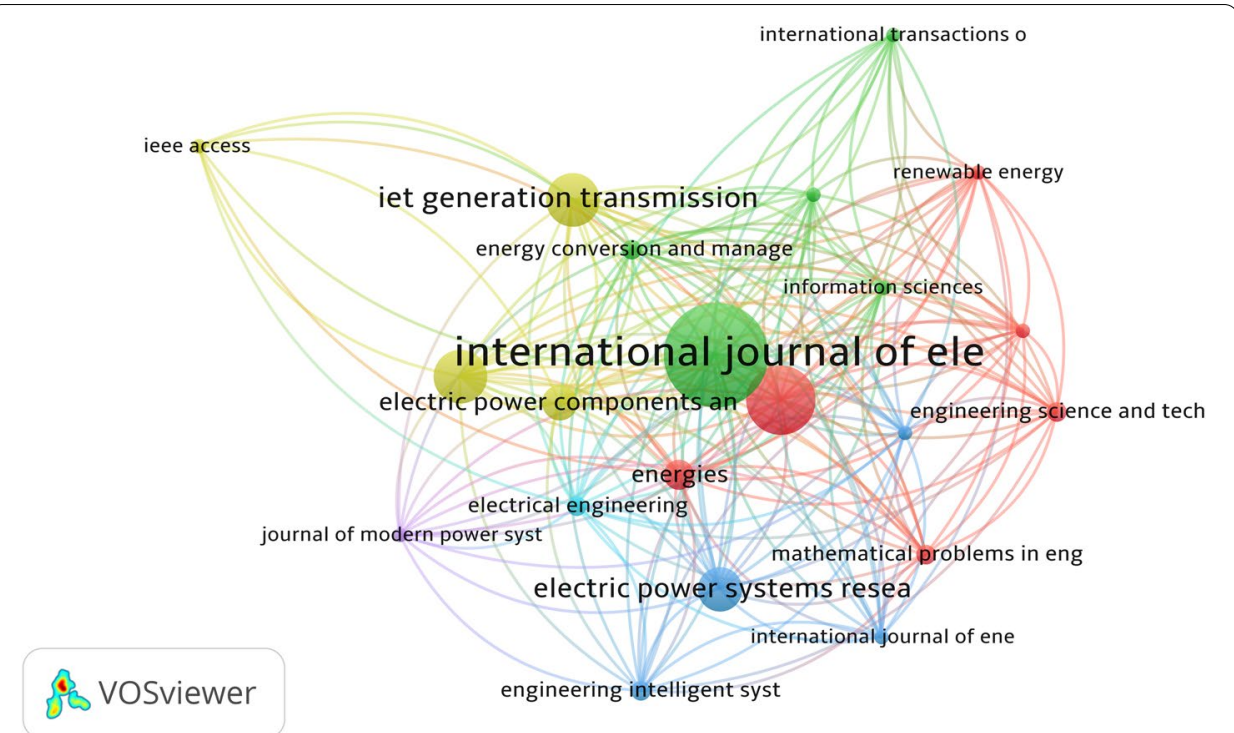

Fig. 16 Journal visualisation network chart'

Table 3 Journal list with ORPD record $\geq 2$

\begin{tabular}{|c|c|c|c|c|c|}
\hline Journal & Record & Country/region & $\begin{array}{l}\text { Impact } \\
\text { factor } \\
(2018)\end{array}$ & CiteScore (2018) & SJR (2018) \\
\hline $\begin{array}{l}\text { International Journal of Electrical } \\
\text { Power \& }\end{array}$ & 23 & England & 4.418 & 5.79 & 1.26 \\
\hline Applied Soft Computing & 14 & Netherlands & 4.873 & 6.27 & 1.22 \\
\hline IEEE Transactions on Power Systems & 10 & USA & 6.807 & 6.77 & 3.14 \\
\hline $\begin{array}{l}\text { IET Generation Transmission and } \\
\text { Distribution }\end{array}$ & 10 & England & 3.229 & 4.25 & 1.099 \\
\hline Electric Power Systems Research & 8 & Switzerland & 3.022 & 4.05 & 1.037 \\
\hline $\begin{array}{l}\text { Electric Power Components and } \\
\text { Systems }\end{array}$ & 6 & USA & 0.888 & 1.48 & 0.345 \\
\hline Electrical Engineering & 3 & USA & 1.296 & 1.81 & 0.26 \\
\hline Energy Conversion and Management & 3 & England & 7.181 & 7.87 & 2.730 \\
\hline $\begin{array}{l}\text { Engineering Science and Technology- } \\
\text { An International Journal-JESTECH }\end{array}$ & 3 & Netherland & - & 4.85 & 0.765 \\
\hline $\begin{array}{l}\text { Mathematical Problems in Engineer- } \\
\text { ing }\end{array}$ & 3 & USA & 1.179 & 1.130 & 0.27 \\
\hline Archives of Electrical Engineering & 2 & Poland & - & 1.09 & 0.221 \\
\hline $\begin{array}{l}\text { Engineering Applications of Artificial } \\
\text { Intelligence }\end{array}$ & 2 & England & 3.526 & 4.58 & 0.881 \\
\hline IEEE access & 2 & USA & 4.098 & 4.96 & 0.61 \\
\hline Information Sciences & 2 & USA & 5.524 & 6.90 & 1.620 \\
\hline $\begin{array}{l}\text { International Transactions on Electri- } \\
\text { cal Energy Systems }\end{array}$ & 2 & England & 1.314 & 1.71 & 0.45 \\
\hline Journal of Electrical Systems & 2 & France & - & 0.81 & 0.2 \\
\hline $\begin{array}{l}\text { Journal of Modern Power Systems } \\
\text { and Clean Energy }\end{array}$ & 2 & China & 2.848 & 4.64 & 1.031 \\
\hline Renewable Energy & 2 & England & 5.439 & 4.58 & 1.89 \\
\hline
\end{tabular}


The top three journals with the highest number of published articles are INT J Elec Power ( $n=23$, IF 4.418), Appl Soft Comput ( $n=14$, IF 4.873) and IET Gener Transm Dis $(n=10$, IF 3.229), and IEEE T PowerElectr $(n=10$, IF 6.807) that tied together in the third place. The largest cluster consisted of 12 journals, while the smallest contained only one. An additional factor used in the ranking of journals is the amount of TLCS and TGCS earned by each journal. Figure 17 shows the TGCS earned by journals with at least a total of 30 citations in the ORPD-related articles. It seemed Int J Elec Power, IEEE T Power Syst and Electr Pow Syst Res were the top three journals with 25\%, 22\% and $11 \%$, respectively, while JESTECH took the 14 th position with $0.94 \%$. The remaining 154 journals had a total of $11 \%$.

\section{Co-occurrence of keywords}

In order to measure the co-occurrence link within the ORPD articles keywords, 781 keywords were extracted. However, the number was too large to be classified into comprehensible research clusters. Hence, the keywords were further refined manually to remove those words that appeared twice due to spelling alterations and some redundant words. 115 keywords were finally selected. Figure 18 shows how the keywords are interlinked with each other in the ORPD research domain. Six clusters were formed, with the largest cluster having 26 items and the smallest having 12 items. Cluster \#1 is the one in red colour. As can be seen, it contains two large circles at its centre and some little scattered ones. The size of a circle signifies the total occurrence and link strength of the keyword in the ORPD research field. The dominant research topic represented by the big

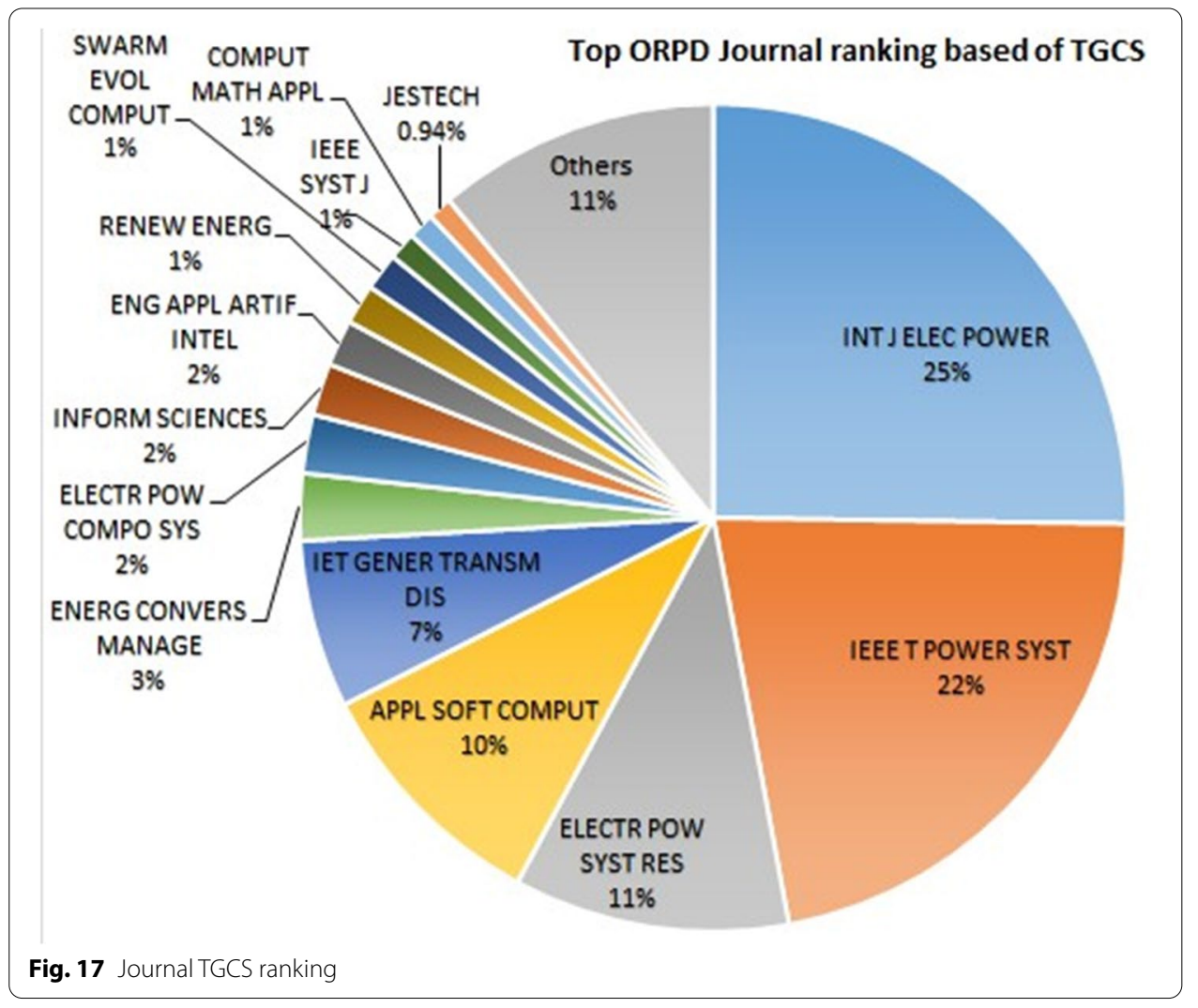




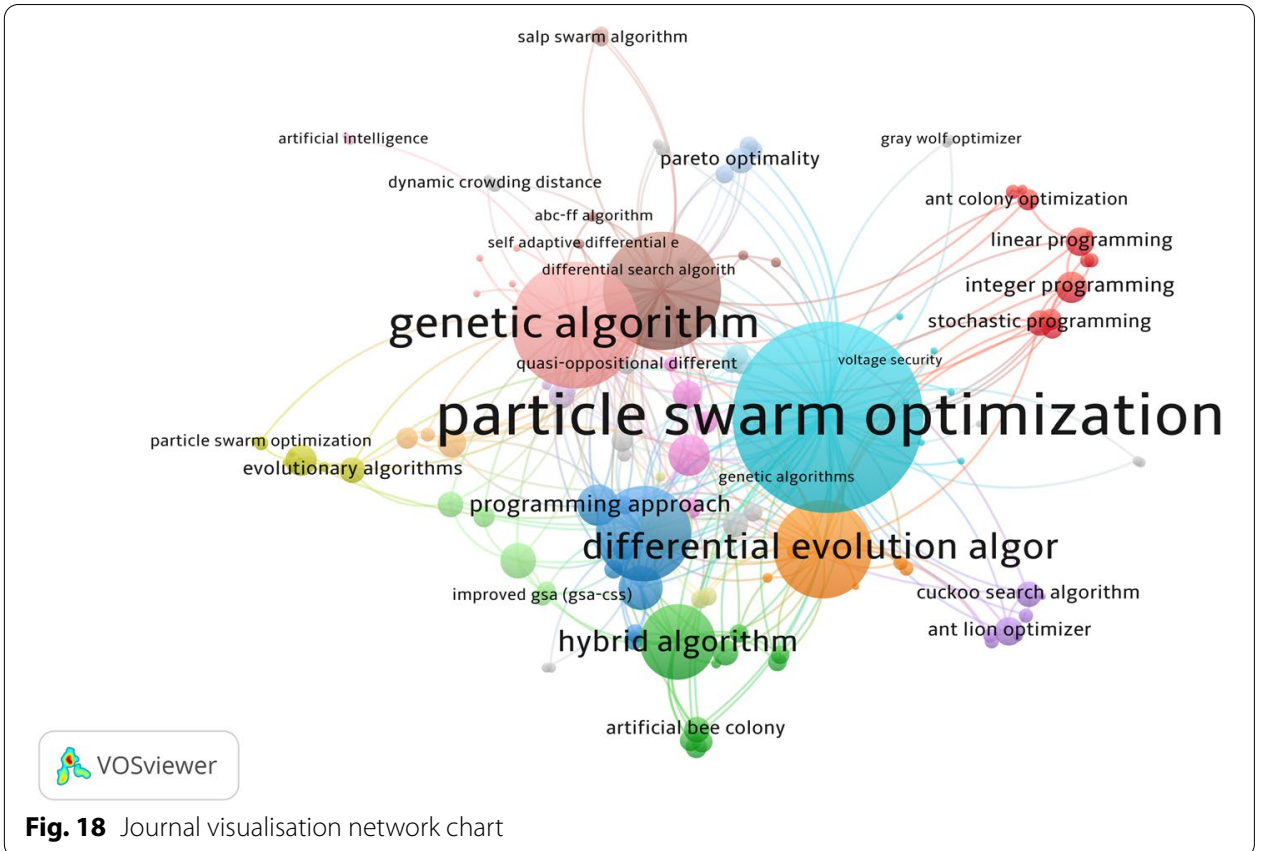

circle is the Genetic Algorithm (GA). GA is a metaheuristic search algorithm inspired by the concept of Darwin's theory of evolution. John Holland first introduced it in 1960, and it used bio-inspired parameters like selection, cross over and mutations to provide an optimal solution to the objective function. GA being among the pioneering optimisers, many articles must have cited it, which perhaps could be the reason for its dominance. Differential Evolution (DE) is equally an evolution-based algorithm with excellent constrained handling capability [48]. Since its inception in 1995 by Storn and Price, it has provided solutions to a lot of constrained based optimisation problems. This feature makes it suitable for ORPD applications [49].

The remaining cluster members are Salp Swarm Algorithm; Chance constrained programming, Symbiotic Organism Search algorithm, Chemical Reaction optimisation (CRO) and Yin-Yang Pair optimisation. Most of which are the trending optimisers and have proven to be effective in handling practical engineering problems.

Cluster \#2 is the one with the sky-blue colour, and it has 23 items. The most prominent research topic is Gravitational Search Algorithm (GSA). GSA was introduced in 2009 by Rashedi et al. with the sole purpose of solving optimisation problems. It is a natureinspired algorithm that was invented based on Newton's gravitational law and the law of motion [50]. The next in the cluster is Bio-geography Base Optimisation (BBO) and was invented by Dan Simon in 2008. Biogeography has a link with the two prominent nineteenth-century scientists, Alfred Wallace and Charles Darwin. Before the 1960 s, biogeography was just a merely descriptive and historical idea, until Robert MacArthur and Edward Wilson collaborate in the early 60s to mathematically model and formulate a theory of Island Biogeography. Their research primary focus was on species migration, emergence of new species and the extinction of a species. The mathematical model of biological genetics and neurons inspired the development of Genetic Algorithms (GAs) and Artificial Neural Network (ANN), so also the biogeography results in the birth of 
Biogeography Base Optimisation (BBO). Since then, research interest has been surging due to its effectiveness in solving various academic and industrial engineering problems [51]. Similar to the previously mentioned optimisers, it optimises an objective function through iterative and stochastic means of improving solutions to a specific quality or a fitness function [51].

The remaining optimisers are Imperialist Competitive Algorithm, Frog-Leafing Algorithm, Jaya Optimisation, Oppositional Krill Herd Algorithm, Teaching Learning Algorithm.

They are all optimisation techniques that are often used to solve not only ORPD research but almost all real-life problems.

Cluster \#3 is the one with a deep blue colour and contains 20 items in all. The most prominent ORPD research optimiser is Particle Swarm Optimisation (PSO) and was initially introduced by Kennedy et al. [52]. It appears to be the most significant research area in the entire clusters, as it has the most significant circle size and is densely connected to all clusters. PSO is a metaheuristic swarm-based optimiser intended to mimic the motion of a flock of birds or school of fish. Its initial purpose was to simulate social behaviour, but later on, it was observed to have performed excellently in solving optimisation problems [53]. The next most popular research optimiser in cluster 3 is the Cuckoo Search Algorithm (CSA). CSA is also a nature-inspired algorithm developed in 2009 by Xin-she Yaang and Suash Debt [54]. The algorithm was derived from the parasitic breeding behaviour of cuckoo species, whereby it laid eggs in the nest of other species of bird resulting in the host bird abandoning its nest to build another one elsewhere [55]. CSA was found to be suitable for various practical optimisation issues, including ORPD research problem [56]. The remaining optimisers are Ant-Lion Optimizers, Gray Wolf Optimizers, Fractal Search Algorithm, Mixed Bacterial chemotaxis, Symbiotic Organism Search Algorithm, Tabu Search Algorithm. All these algorithms gave an insight to interested ORPD researchers on the types and nature of optimisers used in the research field.

Cluster \#4 has 19 keywords, and the yellow colour denotes it. The three dominant research phrases in the cluster are Seeker Optimisation Algorithm (SOA), Artificial Bee Colony Algorithm (ABC), and Double Differential evolution Algorithm (DDE) [57]. SOA is an adequately addressed optimiser and was proposed by Dai et al. [57]. It is an algorithm that exploits the human capability of performing a random search by utilising its history and social experience [57]. Whereas, $\mathrm{ABC}$ is a bio-inspired optimisation algorithm that harnesses the intelligent foraging behaviour of the honey bee. It is a swarmbased optimiser that utilises social cooperation to achieve its tasks successfully. It was developed in 2005 by Dervis Karaboga and has been widely deployed in the field of optimisation to solve ORPD and other various engineering problems [58]. The immune algorithm, Modified Teaching Learning-Based Optimisation, Global Numeric Optimisation and Learning-based optimisation are some of the major trending research optimisers in the cluster.

Cluster \#5 is the one in purple colour and contains 15 research items. The three most dominant are Ant Colony Optimisation (ACO), Linear Programming (LP), and Nonlinear programming. ACO was proposed in 1991 by Marco Dorigo, and it was used to identify the optimal path of a given graph by mimicking the ant food search behaviour. 
Biological Ant uses a pheromone to optimise their exploration and exploitation in the search space, while similarly, in the artificial ant, the quality of result and position are recorded for better solutions. ACO has been used on various engineering applications ranging from sequential ordering, project scheduling, protein folding and ORPD [59]. LP is equally called Successive Linear Optimisation, and it is a method used to maximise or minimise a linear objective function based on linear equality or inequality constraints. It was developed in 1939 by Leonid Kantorovich. It is an optimisation tool used in the power system to minimise the running cost of the network [60].

Cluster \#6 is the last cluster denoted by green colour and contains the least number of keywords (12). The cluster comprises some famous bio-inspired algorithms like Firefly algorithm, Moth- Flame Optimisation (MFO) and Whale Optimisation Algorithm (WOA). The cluster contains hybrid optimisation, which is a combination of two or more algorithmic features to solve the same set of problem. Firefly algorithm is an optimiser inspired by the flashing characteristics of the firefly and was developed by Xin-She Yang in 2008 [61]. The algorithm differs slightly from PSO, which has caused tremendous criticism from some researchers [62]. MFO is a bio-inspired algorithm that mimics the navigational properties of moths fly. It was first developed in 2015 by Mirjalil. Since then, it has been used by researchers to solve complex engineering optimisation problems [63]. WOA is another bio-inspired optimiser that mimics the hunting behaviour of humpback whales. It was proposed in 2016 by the same inventor of MFO. Since its inception, it has been applied to various engineering and real-life problems like ORPD, Maximum power point tracking, Economic dispatch problem, Breast Cancer diagnosis [64]. Table 4 summarises the optimisers having at least two and above occurrences.

\section{Conclusion}

Optimal reactive power dispatch (ORPD) is an essential optimisation aspect in an electrical power system that aids in achieving optimal reliability, security as well as cost-effective operation of the power system network. Its significance is the reason behind the rise in research interest. To generate a summary of the research progress and the future directions, this article has undertaken a bibliometric analysis on ORPD-related publications index in the WoS database covering a period of 30 years (1989-2019). The findings show that 263 articles are published within the period under review, with the highest number of published articles in 2016. However, the annual publications have been declining after 2016, hence reflecting a slight global reduction in ORPD research interest. These articles are published in 166 journals, thereby signifying research diversification. International Journal of Electrical Power and Energy Systems and Applied Soft Computing has the first and second positions, respectively, while IEEE Transaction on Power Systems and IET Generation Transmission and Distribution occupies the third place on the bases of ORPD publications. A total of 571 authors published the 263 articles with Provas, Kumar Roy having the highest number of ORPD articles, while Yi Jia Cao is the author with the highest number of TLCS. ORPD research appears to have broader coverage and active research collaborations among countries like China, USA, England, India, Germany, Algeria, Denmark, Austria, Canada and Morocco. It is interesting to note that the top three countries with the highest research output are from the Asian continent, which is 
Table 4 Keywords with occurrence frequency $\geq 2$

\begin{tabular}{lcc}
\hline Keyword & Occurrence & Link strength \\
\hline Particle Swarm Optimisation & 101 & 749 \\
Genetic Algorithm & 65 & 489 \\
Differential Evolution Algorithm & 41 & 381 \\
Gravitational Search Algorithm & 28 & 248 \\
Linear Programming & 7 & 119 \\
Bio-Geography Based Optimisation & 7 & 76 \\
Artificial Bee Colony & 7 & 31 \\
Cuckoo Search Algorithm & 6 & 34 \\
Ant Colony Optimisation & 5 & 23 \\
Imperialist Competitive Algorithm & 4 & 45 \\
Learning-Based Optimizer & 4 & 42 \\
Ant Lion Optimizer & 4 & 29 \\
NonLinear Programming & 3 & 52 \\
Chaotic Krill Herd Algorithm & 3 & 35 \\
Jaya Search Optimizer & 3 & 22 \\
Tabu Search Optimizer & 3 & 20 \\
Fuzzy Search Algorithm & 2 & 86 \\
Chemical Reaction Optimisation & 2 & 24 \\
Frog Leaping Algorithm & 2 & 19 \\
Pseudo Gradient Search & 2 & 16 \\
Harmony Search Algorithm & 2 & 16 \\
Firefly Search Algorithm & 2 & 15 \\
Symbolic Organism Search Algorithm & 2 & \\
\hline & & 10 \\
\hline
\end{tabular}

probably due to the enormous energy demand and network stress attributed to their large population. One hundred fifteen (115) keywords were used to visualise the cooccurrence networks, which were then classified into six (6) research clusters. The most dominant and trending research topic in each of the six clusters is PSO, GA, GSA, LP, EA and Hybrid Algorithm.

In a nutshell, this study provides valuable outlines and future directions on ORPD research so that both experienced and novice researchers in the field can quickly identify trending research topics, top authors/supervisors, and universities/organisations/industries from which to seek appropriate funding and collaborations.

\footnotetext{
Abbreviations

ORPD: Optimal reactive power dispatch; GA: Genetic algorithm; ES: Evolutionary strategy; PSO: Particle swarm optimisation; BFO: Bacterial foraging optimisation; SADE: Self-adaptive differential evolution; ABC: Artificial bee colony; HSA: Harmony search algorithm; GSA: Gravitational search algorithm; GWO: Grey wolf optimisation; HFA: Hybrid firefly algorithm; TLBO: Teaching-learning-based optimisation algorithm; WoS: Web of science; TGCS: Total global citation scores; TLCS: Total local citation scores; IF: Impact factor; SJR: SCImago journal rank; DE: Differential evolution; CRO: Chemical reaction optimisation; BBO: Bio-geography base optimisation; ICA: Imperialist competitive algorithm; FLA: Frog- leafing algorithm; JO: Jaya optimisation; OKHA: Oppositional Krill Herd algorithm; CSA: Cuckoo search algorithm; ALO: Ant-lion optimisers; FSA: Fractal search algorithm; SOA: Seeker optimisation algorithm; DDE: Double differential evolution; ACO: Ant colony optimisation; LP: Linear optimisation; MFO: Moth-flame optimisation; Swarm Evol Comput: Swarm and evolutionary; INT J Elec Power: International journal of electrical power and energy; Appl Soft Comput: Appl soft computing; IET Gener Transm Dis: IET generation, transmission and distribution; IEEE T Power Syst: IEEE transactions on power systems; Comput Math Appl: Computers and mathematics with applications; Renew Energ: Renewable energy an international journal; Eng Appl Artif Intel: Engineering applications of artificial intelligence; Inform Sciences: Information sciences; Electr Pow Compo Sys: Electric power components and systems; Energ Convers Manage: Energy conversion and management; Electr Pow Syst Res: Electric power systems research; JESTECH: Engineering science and technology, an international journal.
} 


\section{Acknowledgements}

The authors gratefully acknowledge the support from Universiti Malaysia Pahang for providing the enabling research environment.

\section{Authors' contributions}

IH Shanono, A Muhammad performs the data extraction while MC Tiong cross-checked and refined it to avoid duplication. NRH Abdullah and $\mathrm{H}$ Daniyal use HistCite and VOSviewer visualisation software to analyse the data. IH Shanono uses MS Excel to plot some of the graphs. All the authors contributed in result interpretation, drafting and proofreading the manuscript.

\section{Funding}

The authors would like to thank Universiti Malaysia Pahang and Ministry of Higher Education Malaysia for their financial support under the Fundamental Research Grant Scheme (FRGS)(RDU140115).

\section{Availability of data and material}

The datasets generated and analysed during the current study are available from the corresponding author on reasonable request.

\section{Competing interests}

The authors declare that they have no competing interest.

\section{Author details}

${ }^{1}$ Faculty of Electrical and Electronics Engineering, Universiti Malaysia Pahang, 26600 Pekan, Pahang, Malaysia. ${ }^{2}$ Department of Mechatronics, Faculty of the Engineering, Bayero University, Kano, Nigeria.

Received: 13 July 2020 Accepted: 3 December 2020

Published online: 06 January 2021

\section{References}

1. Adewuyi OB, Howlader HOR, Olaniyi IO, Konneh DA, Seniyu T (2020) Comparative analysis of a new VSC-optimal power flow formulation for power system security planning. Int Trans Electr Energy 30(3):1-16

2. Loriya V, Patel V (2016) A review on optimal reactive power dispatch. IJIREEICE 4(1):83-87

3. Conejo AJ, Galiana FD, Kockar I (2001) Z-bus loss allocations. IEEE Trans Power Syst 16(1):105-110

4. Mamundur KRC, Chenoweth RD (1981) Optimal control of reactive power flow for improvements in voltage profiles and for real power loss minimization. IEEE Trans Power Appar Syst 100(7):3185-3194

5. Roy PK, Ghoshal SP, Thakur SS (2012) Optimal VAR control for improvements in voltage profiles and for real power loss minimisation using biogeography based optimisation. Int J Electr Power 43(1):830-838

6. Abdelmoumene M, Mohamed B, Boubakeur A (2013) Optimal reactive power dispatch using differential evolution algorithm with voltage profile control. Int J Intell Syst 5(10):28-34

7. Suresh R, Kumar C, Sakthivel S, Jaisiva S (2013) Application of gravitational search algorithm for real power loss and voltage deviation optimization. Int J Eng Sci Innov Technol 2(1):283-291

8. Ghasemi M, Taghizadeh M, Ghavidel S, Aghaei J, Abbasian A (2015) Solving optimal reactive power dispatch problem using a novel teaching-learning-based optimisation algorithm. Eng Appl Artif Intell 39:100-108

9. Shaheen AM, Spea RS, Farrag SM, Abido MA (2018) A review of meta-heuristic algorithms for reactive power planning problem. Ain Shams Eng J 9(2):215-231

10. Deeb NI, Shahidehpour SM (1988) An efficient technique for reactive power dispatch using a revised linear programming approach. Electr Power Syst Res 15(2):121-134

11. Aoki K, Fan M, Nishikori A (1988) Optimal VAR planning by approximation method for recursive mixed-integer linear programming. IEEE Trans Power Syst 3(4):1741-1747

12. Lo KL, Zhu SP (1991) A decoupled quadratic programming approach for optimal power dispatch. Electr Power Syst 22(1):47-60

13. Granville S (1994) Optimal reactive dispatch through interior point methods. IEEE Trans Power Syst 9(1):136-146

14. Zhao B, Guo CX, Cao YJ (2005) A multiagent-based particle swarm optimisation approach for optimal reactive power dispatch. Power Syst IEEE Trans 20(2):1070-1078

15. Al-Rashidi MR, El-Hawary ME (2009) Applications of computational intelligence techniques for solving the revived optimal power flow problem. Electr Power Syst Res 79(4):694-702

16. Durairaj S, Devaraj D, Kannan PS (2006) Genetic algorithm applications to optimal reactive power dispatch with voltage stability enhancement. J Inst Eng India 87:42-47

17. Wu QH, Cao YJ, Wen JY (1998) Optimal reactive power dispatch using an adaptive genetic algorithm. Int J Electr Power Energy Syst 20(8):563-569

18. Devaraj D (2007) Improved genetic algorithm for multi-objective reactive power dispatch problem. Eur Trans Electr Power 17:569-581

19. Devaraj D, Durairaj S, Kannan PS (2008) Real parameter genetic algorithm to multi-objective reactive power dispatch. Int J Power Energy Syst 28(1):1710-2243

20. Wu QH, Ma JT (1995) Power system optimal reactive power dispatch using evolutionary programming. IEEE Trans Power Syst 10(3):1243-1249

21. Das B, Patvardhan C (2003) A new hybrid evolutionary strategy for reactive power dispatch. Electr Power Syst Res 65(2):83-90

22. Yoshida H, Kawata K, Fukuyama Y, Takamura S, Nakanishi S (2000) A particle swarm optimisation for reactive power and voltage control considering voltage security assessment. IEEE Trans Power Syst 15(4):1232-1239 
23. Esmin AAA, Lambert-Torres G, De- Souza ACZ (2005) A hybrid particle swarm optimisation applied to loss power minimisation. IEEE Trans Power Syst 20(2):859-866

24. Tripathy M, Mishra S (2007) Bacteria foraging-based solution to optimise both real power loss and voltage stability limit. IEEE Trans Power Syst 22(1):240-248

25. Ela AA, Abido MA, Spea SR (2011) Differential evolution algorithm for optimal reactive power dispatch. Electr Power Syst Res 81:458-464

26. Liang CH, Chung CY, Wong KP, Duan XZ, Tse CT (2007) Study of differential evolution for optimal reactive power flow. IEE Proc Gener Transm Distrib 1(2):253-260

27. Ayan K, KIlic U (2012) Artificial bee colony algorithm solution for optimal reactive power flow. Appl Soft Comput 12(5):1477-1482

28. Khazali AH, Kalantar M (2011) Optimal reactive power dispatch based on the harmony search algorithm. Int J Electr Power Energy Syst 33(3):683-692

29. Sinsuphan N, Leeton U, Kulworawanichpong Y (2013) Optimal power flow solution using the improved harmony search method. Appl Soft Comput 13(5):2364-2374

30. Valipour K, Ghasemi A (2017) Using a new modified harmony search algorithm to solve multi-objective reactive power dispatch in deterministic and stochastic models. Al Data Min 5(1):89-100

31. Duman S, Güvenc U, Sönmez Y, Yörükeren N (2012) Optimal power flow using a gravitational search algorithm. Energy Convers Manag 59:86-95

32. Shaw B, Mukherjee V (2014) Solution of reactive power dispatch of power systems by an opposition- based gravitational search algorithm. Int J Electr Power Energy Syst 55:29-40

33. Sulaiman MH, Mustaffa Z, Mohamed MR, Al-iman O (2015) Using the grey wolf optimiser for solving optimal reactive power dispatch problem. Appl Soft Comput 32:286-292

34. Rajan A, Malakar T (2015) Optimal reactive power dispatch using hybrid Nelder-Mead simplex based firefly algorithm. Electr Power Energy Syst 66:9-24

35. Mandal B, Roy PK (2013) Optimal reactive power dispatch using quasi-oppositional teaching learning-based optimisation. Electr Power Energy Syst 53:123-134

36. Muhammad A, Shanono IH (2019) Unmanned underwater vehicle: a bibliometric analysis. J Fundam Appl Sci 12(1S):264-277

37. Roldan-Valadez E, Salazar-Ruiz SY, Ibarra- Contreras R, Rios C (2019) Current concepts on bibliometrics: a brief review about impact factor, eigenfactor score, cites core, SCImago journal rank, source- normalised impact per paper, H-index, and alternative metrics. Ir J Med Sci 188(3):939-951

38. Chen C, Hu Z, Liu S, Tseng H (2012) Emerging trends in regenerative medicine: a scientometric analysis incite space. Expert Opin Biol Ther 12(5):593-608

39. Wang CY, Li BH, Ma LL (2019) The top-100 highly cited original articles on drug therapy for ventilator-associated pneumonia. Front Pharmacol 10:108

40. Muhammad A, Ali MAH, Shanono IH (2020) ANSYS: a bibliometric study. Mater Today Proc 4(2):179-186

41. Corrale IE, Reyes JJ, Fornaris Y (2016) Bibliometric analysis of the Journal of Oral Research, period 2012-2015. J Oral Res 5(5):188-193

42. Baladi ZH, Umedani LV (2017) Pakistan Journal of Medical Sciences: a bibliometric assessment 2001-2010. Pak J Med Sci 33(3):714-719

43. Restrepo G, Willett P (2017) The Journal of Mathematical Chemistry: a bibliometric profile. J Math Chem 55:1589-1596

44. Dehdarirad T, Villarroya A, Barrios M (2015) Research on women in science and higher education: a bibliometric analysis. Scientometrics 103:795-812

45. Wu X, Chen X, Zhan FB, Hong S (2015) Global research trends in landslides during 1991-2014: a bibliometric analysis. Landslides 12(6):1215-1226

46. Olijnyk NV (2015) A quantitative examination of the intellectual profile and evolution of information security from 1965 to 2015. Scientometrics 105(2):883-904

47. Zainab AN, Anyi KWU, Anuar NB (2009) A single journal study: Malaysian Journal of Computer Sciences. Malays J Comput Sci 22(1):1-18

48. Das S, Mullick SS, Suganthan PN (2016) Recent advances in the differential evolution: an updated survey. Swarm Evol Comput 27(1):1-30

49. Storn R, Price K (1997) Differential evolution: a simple and efficient heuristic for global optimisation over continuous spaces. J Glob Optim 11(4):341-359

50. Rashedi E, Nezamabadi-Pour H, Saryazdi S (2009) GSA: a gravitational search algorithm. Inf Sci 179(13):2232-2248

51. Simon D (2008) Biogeography-based optimisation. IEEE Trans Evol Comput 12(6):702-713

52. Kennedy J, Eberhart R (1995) Particle swarm optimization. In: Proceedings of IEEE international conference on neural networks 1995, Perth. Australia: IEEE, pp 1942-1948

53. Kennedy J (1997) The particle swarm: social adaptation of knowledge. In: Proceedings of IEEE international conference on evolutionary computation 1997, Indianapolis. USA. IEEE, pp 303-308

54. Yang XS, Deb S (2010) Cuckoo search via Lévy flights. In: 2009 world congress on nature \& biologically inspired computing (NaBIC), Coimbatore, India. IEEE, pp 210-214

55. Payne RB, Klitz K (2005) Bird families of the world. The cuckoos. Oxford University Press, Oxford, pp 1-644

56. Oliveira VYM, De-Oliveira RMS, Affonso CM (2018) Cuckoo Search approach enhanced with the genetic replacement of abandoned nests applied to the optimal allocation of distributed generation units. IET Gener Transm 12(13):3353-3362

57. Dai C, Zhu Y, Chen W (2006) Seeker optimisation algorithm. In: Wang Y, Cheung Y, Liu H (eds) Computational intelligence and security. CIS 2006. Lecture notes in computer science, vol 4456. Springer, Berlin, pp 167-176

58. Karaboğa D (2019) TECHNICALREPORT-TR06. http://citeseerx.ist.psu.edu/viewdoc/summary?doi=10.1.1.71-4.4934 Accessed 10 Nov 2019

59. Dorigo M, Birattari M, Stutzle T (2006) Ant colony optimization. IEEE Comput Intell Mag 1(4):28-39 
60. Olofsson M, Anderson G, Soder L (1995) Linear programming based optimal power flow using second order sensitivities. IEEE Trans Power Syst 10(3):1692-1697

61. Yang XS (2010) Firefly algorithm. Nature-inspired metaheuristic algorithm, vol 2. Luniver Press, Bristol, pp 81-89

62. Sadeghi J, Saeid S, Niaki S, Akhavan T (2014) Optimising a hybrid vendor-managed inventory and transportation problem with fuzzy demand: an improved particle swarm optimisation algorithm. Inf Sci 271:126-144

63. Mirjalili S (2015) Moth-flame optimisation algorithm: a novel nature-inspired heuristic paradigm. Knowl Based Syst $89: 228-249$

64. Mirjalili S, Lewis A (2016) The whale optimisation algorithm. Adv Eng Softw 95:51-67

\section{Publisher's Note}

Springer Nature remains neutral with regard to jurisdictional claims in published maps and institutional affiliations.

Submit your manuscript to a SpringerOpen ${ }^{\circ}$ journal and benefit from:

- Convenient online submission

Rigorous peer review

- Open access: articles freely available online

- High visibility within the field

- Retaining the copyright to your article

Submit your next manuscript at $\gg$ springeropen.com 